\title{
The Research of Influence of Graphite Quality on Mold Coatings for Low-Pressure Die Casting
}

\author{
Pavel Yu. Barbitsky*a, Tatiana A. Bogdanova ${ }^{a}$, \\ Tatiana R. Gilmanshina ${ }^{\mathrm{b}}$, Nikolay N. Dovzhenko, \\ Aleksander V. Cheglakova, Svetlana I. Lytkinab, \\ Aleksander A. Kosovich ${ }^{b}$ and Evgeny G. Partyko ${ }^{b}$ \\ ${ }^{a} K \& K$ ltd. \\ 3 Berezina, Krasnoyarsk, 660020, Russia \\ ${ }^{b}$ Siberian Federal University \\ 79 Svobodny, Krasnoyarsk, 660041, Russia
}

Received 26.02.2015, received in revised form 18.04.2015, accepted 02.07.2015

The influence of content of cryptocrystalline graphite of Kureysk Field, activated in a planetary centrifugal mill AGO-2, on the technological properties of mold coatings used for low-pressure die casting and castability of AK12 alloy are researched. It was found that the optimum properties of coating are achieved by the introduction into their composition $15 \mathrm{wt} . \%$ of activated graphite. Also it was found that with increasing content of graphite, the castability of AK12 alloy and roughness of castings are decreases. The comparative laboratory and pilot testing of coatings based on natural, enriched and activated graphite showed that coatings based on activated graphite can be recommended for molds.

Keywords: natural graphite, activated graphite, enriched graphite, low-pressure die casting, mold, release coatings, AK12 alloy.

DOI: 10.17516/1999-494X-2015-8-5-663-668.

(c) Siberian Federal University. All rights reserved

* Corresponding author E-mail address: bpy@kandk.ru; bat@kandk.ru 


\title{
Исследование влияния качества графита
}

\section{на покрытия пресс-форм}

\section{для литья под низким давлением}

\author{
П.Ю. Барбицкий ${ }^{a}$, Т.А. Богданова ${ }^{a}$, \\ Т.Р. Гильманшина ${ }^{\sigma}$, Н.Н. Довженко \\ С.И. Лыткина ${ }^{\sigma}$, А.А. Косович ${ }^{\sigma}$, Е.Г. Партыко ${ }^{\sigma}$ \\ ${ }^{a} O O O$ «KuK» \\ Россия, 660020, Красноярск, Березина, 3 \\ ${ }^{6}$ Сибирский федеральный университет \\ Россия, 660041, Красноярск, Свободньй, 79
}

Изучено влияние содержания активированного в планетарно-центробежной мельнице АГО2 скрытокристаллического графита Курейского месторождения на технологические свойства покрытий пресс-форм, используемых для литья под низким давлением, жидкотекучесть сплава АК12. Установлено, что наиболее оптимальные свойства покрытий достигаются при введении в их состав 15 мас. \% активированного графита. Выяснено, что с увеличением содержания графита жидкотекучесть сплава АК12 и шероховатость отливок снижается. Проведённые сравнительные лабораторные и опытно-промышленные испытания покрытий на основе природного, активированного и обогащенного графита показали, что для покрытий пресс-форм могут быть рекомендованы покрытия на основе активированного графита.

Ключевые слова: природный графит, активированный графит, обогащенный графит, литье под низким давлением, пресс-форма, разделительные покрытия, сплав АК12.

Современные тенденции конкурентной борьбы на постоянно растущем рынке легкосплавных дисков требуют от производителей уделять особое внимание технологиям и методам, применяемым для повышения качества продукции и снижения затрат. Одним из эффективных способов считают применение разделительных покрытий, которые должны обладать высокими технологическими и эксплуатационными свойствами: простота нанесения, высокая кроющая способность, седиментационная устойчивость, адгезия к материалу пресс-формы. Чем выше эти свойства, тем больше можно произвести заливок расплава в пресс-форму перед повторным нанесением покрытия [1, 2].

В настоящее время российские производители легкосплавных дисков и других фасонных изделий методом литья под давлением или литья под низким давлением в большинстве своём закупают подобные покрытия за рубежом, так как существующие немногочисленные отечественные аналоги должным образом не обеспечивают выполнения требований, предъявляемых к покрытиям.

Целью данной работы стало изучение влияния качества графита и его содержания на технологические свойства разделительных покрытий и на жидкотекучесть сплава АК12.

Работа выполнена на ООО «КиК» и в лабораториях ИЦМиМ СФУ.

Исследование технологических свойств покрытий (плотность, вязкость, седиментационная устойчивость, приведённая прочность) проводили согласно ГОСТ 10772-78; оценку влия- 
ния покрытий на жидкотекучесть расплава - по спиральным пробам (ГОСТ 16438-70, температура пресс-формы $100{ }^{\circ} \mathrm{C}$, температура расплава $\left.710^{\circ} \mathrm{C}\right)$.

Использование графита обусловлено его высокой теплопроводностью, позволяющей избежать переохлаждения пресс-формы, что способствует устранению такого дефекта литья под низким давлением, как заворот окисной плены. Из литературы $[3,4]$ известно, что в качестве добавок для покрытий рекомендуется использовать графиты с низким содержанием золы: скрытокристаллические ГЛС-1 и ГЛС-2, кристаллические ГЛ-1, ГЛ-2.

В Красноярском крае сосредоточены большие запасы природного скрытокристаллического графита, поэтому для исследований были выбраны следующие марки графитов:

- ГЛС-2 - природный скрытокристаллический графит (ГОСТ 17022-81);

- ГЛС-2А - активированный в планетарно-центробежной мельнице АГО2 по режимам, описанным в работах $[5,6]$;

- ГЛС-0 - обогащенный графит с содержанием золы 2-4 \%, технологические режимы подготовки которого описаны в работе [7].

Покрытия наносили на форму в несколько проходов распылителем, в котором используется сжатый воздух под высоким давлением, что позволяет получить равномерный слой без подтёков (35-40 мкм) [8].

Технологические свойства исследуемых покрытий представлены в табл. 1, на рис. 1 .

Из представленных результатов видно, что с увеличением содержания графита повышаются основные технологические свойства покрытий: плотность, вязкость, седиментационная устойчивость. Введение графита в количестве более чем 15 мас. \% приводит к снижению прочности. С увеличением содержания графита жидкотекучесть расплава АК12 и шероховатость отлитых образцов заметно снижается, что связано с изменением интенсивности теплообмена в системе расплав-покрытие-форма и отводом тепла от металла к поверхности формы. Анализ

Таблица 1. Технологические свойства покрытий с различным содержанием графита

\begin{tabular}{|c|c|c|c|c|c|c|c|c|c|c|}
\hline \multirow{4}{*}{ Свойство } & \multicolumn{10}{|c|}{ Покрытие } \\
\hline & \multicolumn{5}{|c|}{$\begin{array}{c}\text { для окраски пуансонов } \\
\text { литейных машин }\end{array}$} & \multicolumn{5}{|c|}{ заводских пресс-форм } \\
\hline & \multicolumn{10}{|c|}{ Содержание графита } \\
\hline & 0 & 5 & 10 & 15 & 20 & 0 & 5 & 10 & 15 & 20 \\
\hline 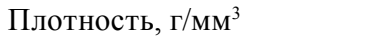 & 1110 & 1120 & 1130 & 1155 & 1170 & 1040 & 1050 & 1055 & \multicolumn{2}{|c|}{1080} \\
\hline Вязкость, с & 10 & 12 & 14 & 16 & 16 & 10 & 11 & 12 & \multicolumn{2}{|c|}{14} \\
\hline $\begin{array}{l}\text { Седиментационная } \\
\text { устойчивость, \%, через ч: } \\
0,5 \\
1 \\
3 \\
7 \\
24\end{array}$ & $\begin{array}{c}100 \\
100 \\
100 \\
92 \\
85\end{array}$ & $\begin{array}{l}43 \\
34 \\
30 \\
28 \\
28\end{array}$ & $\begin{array}{l}64 \\
49 \\
42 \\
41 \\
41\end{array}$ & $\begin{array}{l}72 \\
60 \\
57 \\
57 \\
57\end{array}$ & $\begin{array}{l}82 \\
73 \\
68 \\
68 \\
67\end{array}$ & $\begin{array}{l}99 \\
98 \\
97 \\
95 \\
87\end{array}$ & $\begin{array}{l}20 \\
20 \\
19 \\
19 \\
18\end{array}$ & $\begin{array}{l}22 \\
22 \\
20 \\
20 \\
20\end{array}$ & $\begin{array}{l}41 \\
37 \\
34 \\
33 \\
33\end{array}$ & $\begin{array}{l}46 \\
38 \\
36 \\
35 \\
35\end{array}$ \\
\hline $\begin{array}{l}\text { Приведённая прочность, } \\
\text { г/мм }\end{array}$ & 29400 & 22118 & 25620 & 29524 & 24950 & 850 & 55 & 225 & 253 & 150 \\
\hline
\end{tabular}




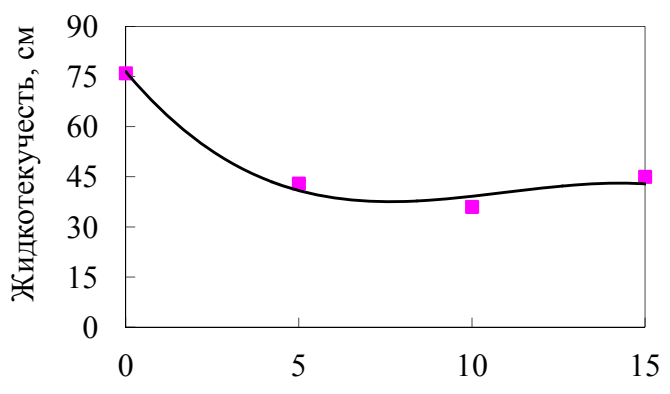

Содержание графита, \%

a

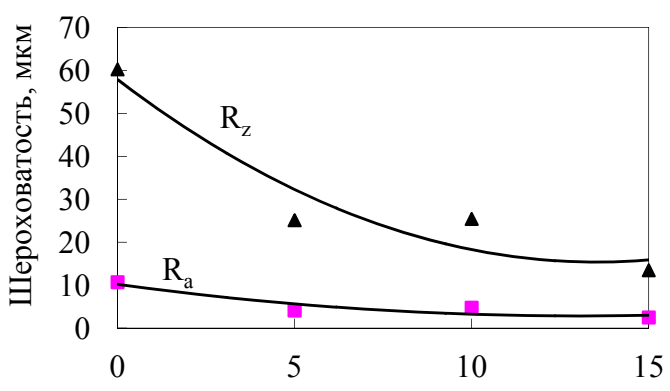

Содержание графита, \% б

Рис. 1. Жидкотекучесть (а) и шероховатость образцов (б), полученных с применением покрытия для окраски пуансонов литейных машин с содержанием графита 15 мас. \%

Таблица 2. Влияние качества графита и его содержания на жидкотекучесть сплава АК12 (покрытие для окраски пуансонов литейных машин), см

\begin{tabular}{|c|c|c|c|}
\hline \multirow{2}{*}{ Содержание графита, $\%$} & \multicolumn{3}{|c|}{ Графит } \\
\cline { 2 - 4 } & ГЛС-2 & ГЛС-2А & ГЛС-0 \\
\hline 0 & \multicolumn{3}{|c|}{76} \\
\hline 5 & 36 & 43 & 39 \\
\hline 10 & 34 & 36 & 36 \\
\hline 15 & 40 & 45 & 41 \\
\hline 20 & 33 & 23 & 38 \\
\hline
\end{tabular}

полученных данных показывает, что наиболее оптимальное содержание графита в покрытии 15 мac. $\%$.

Сравнение результатов жидкотекучести при использовании покрытии на основе графитов различного качества приведено в табл. 2.

Сравнение данных показало, что наименьшее снижение жидкотекучести наблюдается при введении в состав покрытия графита ГЛС-2А.

С учётом полученных данных следующая серия экспериментов проводилась с заводских пресс-форм только при добавлении графита ГЛС-2А (рис. 2).

В производственных условиях ООО «КиК» заводская пресс-форма была окрашена покрытием, содержащим 15 \% графита ГЛС-2А (рис. 3, 4).

Результаты испытаний показали, что индекс пористости отливки, полученной с серийно применяемым покрытием, составил 4,4 \%, а отливки, полученной с графитовым покрытием, 3,0 \%. На поверхности экспериментальных отливок наблюдается слой мелких кристаллов толщиной 3-4 мм. На 10-15 \% сократился брак по оксидным пленкам.

Таким образом, для дальнейших исследований можно рекомендовать графит, активированный в планетарно-центробежной мельнице АГО2, в количестве 15 мас. \%. 


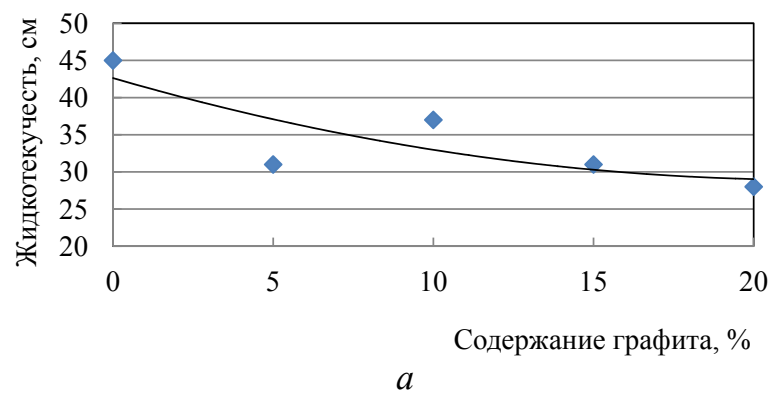

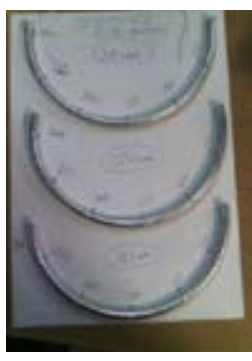

6

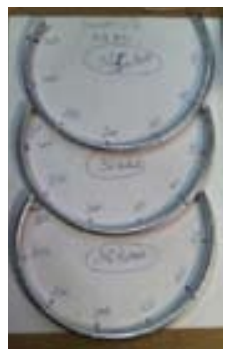

B

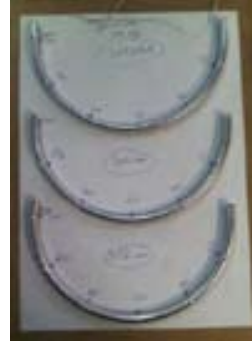

2

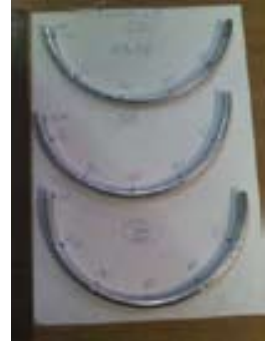

$\partial$

Рис. 2. Влияние содержания графита ГЛС-2А в заводских пресс-формах жидкотекучесть сплава АК 12 , \%: а - зависимость; б $-5 ;$ в $-10 ; \Gamma-15 ;$ д -20

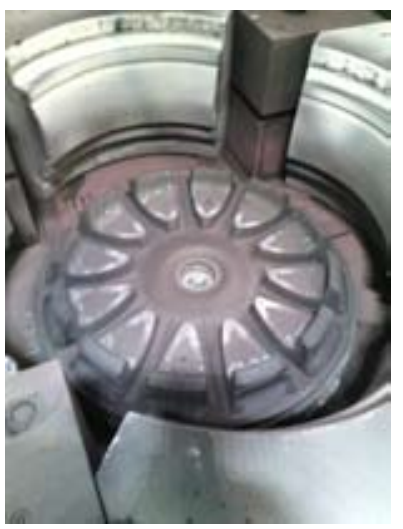

Рис. 3. Пресс-форма, окрашенная покрытием с графитом ГЛС-2А 


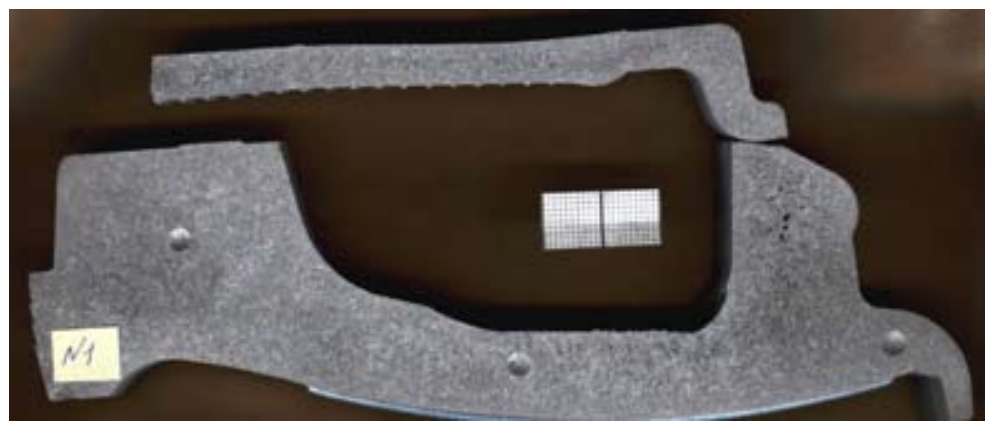

$a$

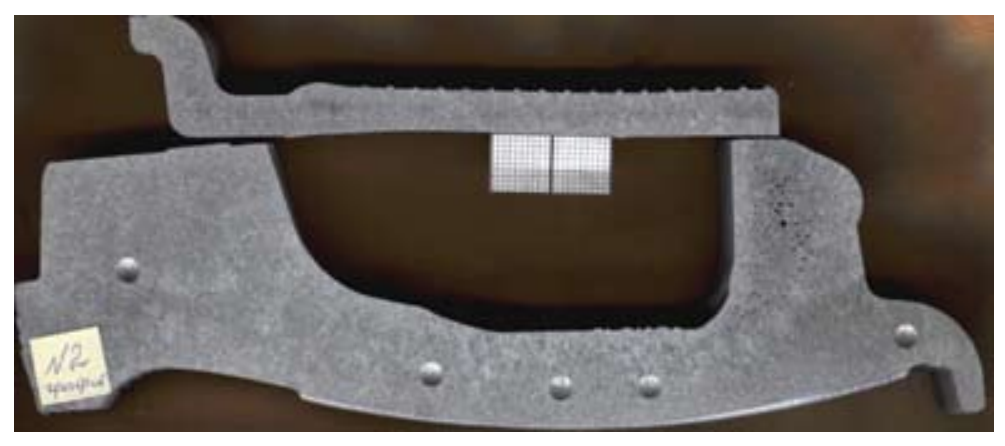

$\sigma$

Рис. 4. Сечение экспериментального колеса: а - покрытие без графита, б - покрытие с содержанием графита $15 \%$

\section{Список литературы}

[1] Аналитический бюллетень. Металлургия: тенденции и прогнозы // ООО РА «РИА Рейтинг». 2013. № 12.34 с.

[2] Галдин Н.М., Чернега Д.Ф., Иванчук Д.Ф. и др. Цветное литье: справочник / ред. Н.М. Галдин. М.: Машиностроение, 1989. 528 с.

[3] Болдин А.Н., Давыдов Н.И., Жуковский С.С. и др. Литейные формовочные материалы. Формовочные, стержневые смеси и покрытия: справочник. М.: Машиностроение, 2006. 507 с.

[4] Жуковский С.С., Анисович Н.И. и др. Формовочные материалы и технология литейной формы: справочник / ред. С.С. Жуковский. М.: Машиностроение, 1993. 432 с.

[5] Баранов В.Н. Автореф. дис. ... канд. техн. наук. Красноярск, 2005. 26 с.

[6] Мамина Л. И., Аникина В.И., Гильманшина Т.Р. и др. // Порошковая металлургия и функциональные покрытия. 2014. № 3. С. 21-25.

[7] Гильманшина Т.Р. Автореф. дис. ... канд. техн. наук. Красноярск, 2004. 24 с.

[8] Барбиикий П.Ю., Богданова Т.А., Гильманшина Т.Р. и др. // Цветные металлы - 2014: сб. тезисов докладов V междунар. конгресса. Красноярск, 2014. С. 366-367. 